\title{
Identification and Molecular Characterization of the Most Common Types of Beta Thalassemia Mutations in Sudanese Patients
}

\author{
Rabab Hassan Elshaikh ${ }^{* 1}$ and Sanaa Elfatih Hussein ${ }^{2}$ \\ ${ }^{1}$ Department of Hematology and Immunohematology, University of Gezira, Sudan \\ ${ }^{2}$ Faculty of medical laboratory science, University of Gezira, Sudan \\ *Corresponding author: Rabab Hassan Elshaikh, Department of Hematology and Immunohematology, University of Gezira, Sudan. \\ To Cite This Article: Rabab Hassan Elshaikh, Sanaa Elfatih Hussein Identification and Molecular Characterization of the Most Common Types of \\ Beta Thalassemia Mutations in Sudanese Patients. Am J Biomed Sci \& Res. 2019 - 6(3). AJBSR.MS.ID.001037. DOI: 10.34297/AJBSR.2019.06.001037.
}

Received: 㠿 November 15, 2019; Published: 眥 November 25, 2019

\begin{abstract}
Thalassemia is a common inherited disorder among humans, and they represent a major public health problem in many areas of the world. The spectrum of mutations varies significantly between different geographical regions; only a few common mutations of $\beta$-globin cause $\beta$-thalassemia in each population. This is a cross-sectional study conducted in Sudan, among 61 known beta thalassemic patients arrived at public health hospitals of Khartoum State, during the period of July 2017 to July 2019. The study was aimed to detect the most common types of mutations in Beta Thalassemic Sudanese patient in Khartoum State. Blood samples from 61 beta thalassemic patients were analyzed to detect the most common types of mutations in Beta Thalassemia using PCR assay. the frequency of adults (>18 years) was 45 (73.8\%), and $16(26.2 \%)$ were Children ( $<18$ years)., The frequency of male to female was $27(44.3 \%)$ and $34(55.7 \%)$ respectively. The results obtained were, 25 patients positive and 36 patients were negative to 5 mutations including in the study. The frequency of positive mutations to IVS-I-110 $(\mathrm{G} \rightarrow \mathrm{A})$ were $14(56 \%)$ common one followed by IVS-I-6 (T $\rightarrow \mathrm{C})$ mutation were positive in 7 patients (28\%) and IVS-I- $(\mathrm{G} \rightarrow \mathrm{A})$ mutation was seen in $4(16 \%)$ patients, whereas $36(59 \%)$ patients show negative for $\beta I V S-I-5(G \rightarrow C)$ and -87 which were not detected in the present study. This preliminary information regarding the mutational pattern is important for establishing prenatal diagnosis programs. The results showed that, IVS-1-110 $(\mathrm{G} \rightarrow \mathrm{C})$ mutations is the most frequent mutation encountered among the beta thalassaemic samples.
\end{abstract}

Keywords: Thalassemia; Mutations; PCR; IVSI; Sudan; Hemoglobinopathy

\section{Introduction}

Thalassemia is a Mendelian autosomal recessive heritable blood disorder it's a group of genetically determined microcytic, hypochromic anemia's resulting from decrease in synthesis of one or more globin chains in the hemoglobin molecule. The most common types are alpha and beta thalassemia according to which globin chain is reduced. Thalassemia was first described by [1] when he observed the disorder in patients of Mediterranean ancestry, and called Cooley's anemia, In 1936 Whipple and Bradford in describing the pathological changes of the condition for the first time coined the name thalassemia, which means "sea in the blood "which is a reference to the fact that thalassemia is prevalent in the Mediterranean Sea area [2]. Thalassemia was historically found in warmer areas of the world and became prevalent in those areas because they coincide with the areas where malaria is also prevalent, and thalassemia provides some protection against malaria, resulting in more thalassemia's carriers surviving malaria epidemics than non-thalassemia's, thereby inflating the percentage of those populations carrying the thalassemia genes [1,3]. The genetic defect involved in beta thalassemia is usually a missense or nonsense mutation in the beta-globin gene, although occasional defects due to gene deletions of the beta-globin gene and surrounding regions have also been reported. The severity of the damage depends on the nature of the mutation. Mutations in the HBB gene cause beta thalassemia. The HBB gene provides instructions for making a protein called betaglobin. Beta-globin is a component (subunit) of hemoglobin. Beta thalassemia mutations are characterized according to the extent of defect information of beta-globin chains, some mutations in the 
HBB gene prevent the production of any beta-globin. The absence of beta-globin is referred to as beta-zero (B0) thalassemia. Other HBB gene mutations allow some beta-globin to be produced but in reduced amounts. A reduced amount of beta-globin is called beta-plus $(\mathrm{B}+)$ thalassemia. Having either $\mathrm{B} 0$ or $\mathrm{B}+$ thalassemia does not necessarily predict disease severity, however; people with both types have been diagnosed with thalassemia major and thalassemia intermedia [4]. A lack of beta-globin leads to a reduced amount of functional hemoglobin. Without enough hemoglobin, red blood cells do not develop normally, causing a shortage of mature red blood cells. The low number of mature red blood cells leads to anemia and other associated health problems (GHR, 2002). Beta thalassemia is a common blood disorder worldwide and is found in Greeks, Mediterranean origin peoples, Middle East India, South east Asia and in Blacks. No population group is completely free from the condition, and it is now occasionally identified in person of Northern European Origin. Gene frequencies for the $\alpha$ and $\beta$ thalassemia on a global basis range from $1 \%$ to more than $80 \%$ in areas where malaria is endemic [5]. Although reliable data are still lacking for many regions of the world, recent data indicate that about $7 \%$ of the world's population is a carrier of a hemoglobin disorder, and that 300,000-500,000 children are born each year with the severe homozygous states of these diseases. Thalassemia, including $\mathrm{HbE}$, is more prevalent in the Mediterranean basin, the Middle East, Southern and Eastern Asia, the South Pacific and South China, with reported carrier rates ranging from $2 \%$ to $25 \%$ as mentioned in "Guidelines to the Clinical Management of Thalassemia [6]. Haemoglobinopathies including the thalassemia and sickle cell disease are known to be prevalent inherited disorders in most Arab countries with varying prevalence rates and molecular characterization. $\beta$-thalassemia is encountered in polymorphic frequencies in almost all Arab countries with carrier rates of 1-11 $\%$ and a varying number of mutations [7]. Sudan is a diverse country with a complex population originating from different ethnic groups; this reflects a matter of various intermarriage and social interaction status. Prevention of $\beta$-thalassemia implies knowledge of molecular mutations and genotypes present in the beta thalassemia. So, the detection of all mutations of $\beta$ - thalassemia in each population is the major goal in prevention [8].

\section{Materials and Methods}

A cross-sectional descriptive study was carried out to detect the most common types of mutations in Beta Thalassemia Sudanese patient in Khartoum State Sudan, during the period of July 2017 to July 2019. From each patient, $2.5 \mathrm{ml}$ of venous blood sample was collected in sterile EDETA container. The blood samples were analyzed for Complete blood count (CBC) using the automated hematology analyzer (SYSMEX KX- 21N), within 24 hours of blood collection. On the same day itself the blood samples were screened for haemoglobinopathies and those samples were stored in $-20^{\circ} \mathrm{C}$ freezer for later molecular analysis. The inclusion criteria Patients were diagnosed as Beta -thalassemia, availability of patient demographic data and laboratory reports, (CBC, Hemoglobin electrophoresis, and peripheral blood picture, Iron studies), Patients not diagnosed as Beta-thalassemia or coexisted with other hemoglobin variants or with other hematological malignancy were excluded from the study. The objective of the study explained to all individuals participating in this study. An informed written consent obtained from all participants.

DNA was extracted from $300 \mu \mathrm{l}$ blood sample, following SDS and Proteinase K extraction method [9]. The purified DNA was dissolved in $100 \mu \mathrm{l}$ of TE buffer and stored at $-20^{\circ} \mathrm{C}$ until tested by PCR.

PCR was performed using the primers described by [7]. The nucleotide substitution in the primers was focused on nucleotide position of IVSI- 6 and IVSI-110. Primer nucleotide sequences, the primer combination for each reaction and amplification product length are listed in Table 1. For each reaction, $5 \mu$ l PCR master mix (Solis Bio dyne master mix), $8 \mu$ deionized water, $5 \mu$ l DNA template and $0.5 \mu \mathrm{l}$ of each allele specific primers in one micro-tube were mixed. PCR was performed in a thermal cycler (Techne, UK). In the first reaction, IVSI-6 ( $\mathrm{T} \rightarrow \mathrm{C}$ ) primer pair was used to amplify the 449 bp fragment to detect the normal alleles. The IVSI- $6(\mathrm{~T} \rightarrow \mathrm{C})$ mutant primer pair in the second reaction was selected to amplify the $286 \mathrm{bp}$ fragment for mutant allele detection. In the third reaction, the IVSI-110 $(\mathrm{G} \rightarrow \mathrm{A})$ primer pair was selected to amplify the 419 bp product to detect normal DNA sequence at this point. Finally, in the fourth reaction, the mutant IVSI-110 $(\mathrm{G} \rightarrow \mathrm{A})$ primer pair was applied to produce the $419 \mathrm{bp}$ fragment to detect the point mutation at this position. In each PCR, specific primers were used as internal positive control that produces a $861 \mathrm{bp}$. The cycling conditions were an initial denaturation for $3 \mathrm{~min}$ at $95^{\circ} \mathrm{C}$, followed by 35 cycles of $60 \mathrm{sec}$ at $94^{\circ} \mathrm{C}, 60 \mathrm{sec}$ at $60^{\circ} \mathrm{C}, 90 \mathrm{sec}$ at $72^{\circ} \mathrm{C}$ and an additional $3 \mathrm{~min}$ at $72^{\circ} \mathrm{C}$ for final extension. $5 \mu \mathrm{l}$ of the PCR product was analyzed by gel electrophoresis [7].

Table 1: PCR primers sequence used for $\beta$-globin gene mutation.

\begin{tabular}{|c|c|c|}
\hline Mutation name & Primer pair & Fragment size (bp) \\
\hline Normal IVS1-6 & F:5'AGTTGGTGGTGAGGCCCTGGGCAGGTTGGT '3 & 449 \\
\hline Mutant IVS1-6 & R:5'CCCCTTCCTATGACATGAACTTAA'3 & 286 \\
\hline
\end{tabular}




\begin{tabular}{|c|c|c|}
\hline Normal IVS1-110 & $\begin{array}{c}\text { F:5’ACCAGCAGCCTAAGGGTGGGAAAATACACC ‘3 } \\
\text { R:5’ACCTCACCCTGTGGAGCCAC ‘3 }\end{array}$ & 419 \\
\hline Mutant IVS1-110 & $\begin{array}{c}\text { F:5’ACCAGCAGCCTAAGGGTGGGAAAATAGAGT '3 } \\
\text { R:5’ACCTCACCCTGTGGAGCCAC ‘3 }\end{array}$ & 419 \\
\hline Normal IVS1-5 & $\begin{array}{c}\text { F:5 CTCCTTAAACCTGTCTTGTAACCTTGTTAC’3 } \\
\text { R:5ACCTCACCCTGTGGAGCCAC’3 }\end{array}$ & 285 \\
\hline Mutant IVS1-5 & $\begin{array}{c}\text { F:5'CTCCTTAAACCTGTCTTGTAACCTTGTTAG'3 } \\
\text { R:5'ACСTCACCCTGTGGAGCCAC'3 }\end{array}$ & 285 \\
\hline Mutant IVSI-1 & $\begin{array}{l}\text { F:5 TTAAACCTGTCTTGTAACCTTGATACGAATC'3 } \\
\text { R:5'TTAAACCTGTCTTGTAACCTTGATACGAACC'3 }\end{array}$ & 218 \\
\hline Mutant -87 & $\begin{array}{l}\text { F:5CTCACCCTGTGGAGCCACACGCTAGGGTTGGCCAATCTAC'3 } \\
\text { R:5GTAGATTGGCCAACCCTAGCGTGTGGCTCCACAGGGTGAG’3 }\end{array}$ & 289 \\
\hline Control & $\begin{array}{l}\text { F: 5'-GAGTCAAGGCTGAGAGATGCA GGA-'3 } \\
\text { R: 5'-CAATGTATCATGCCT CTTTGC ACC-'3 }\end{array}$ & 861 \\
\hline
\end{tabular}

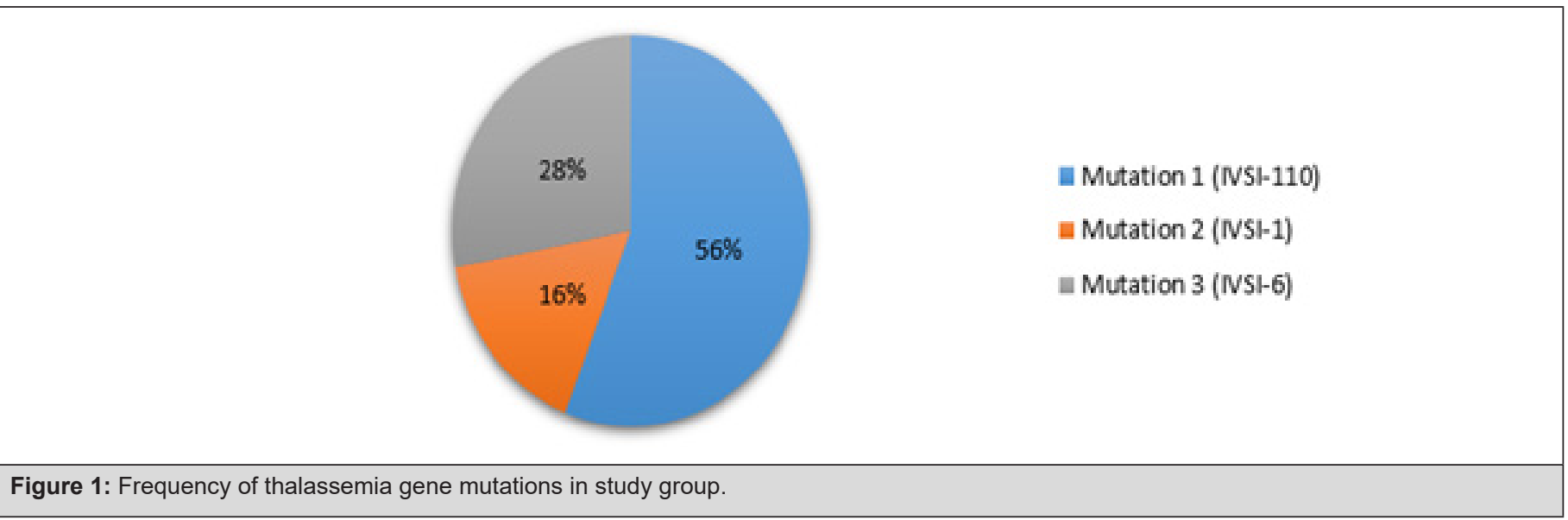

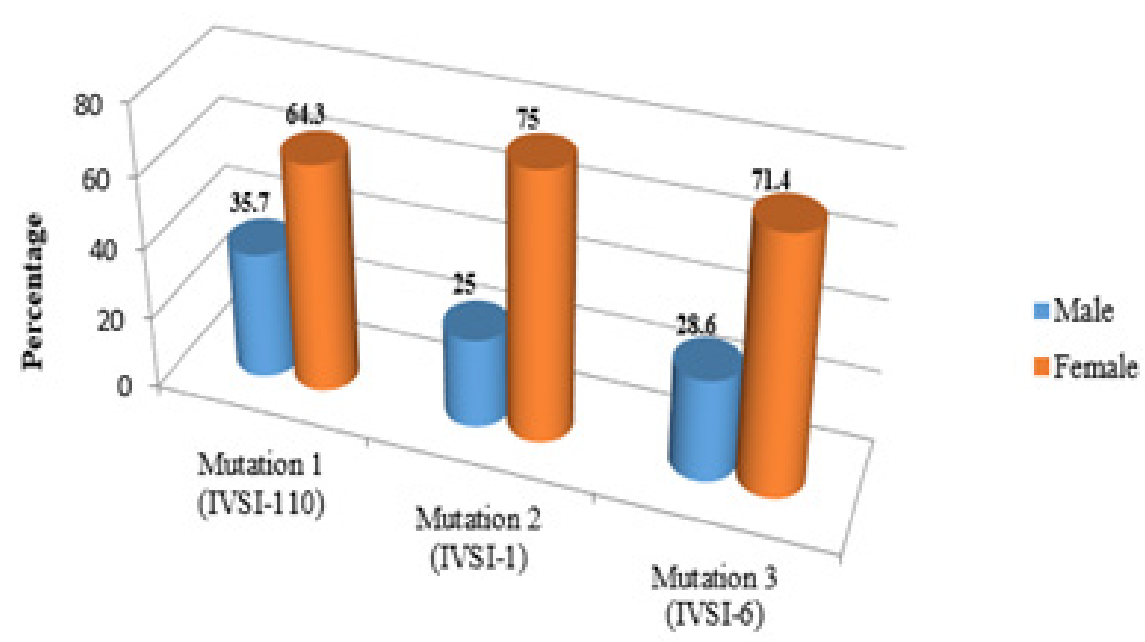

Figure 2: Frequency of different mutations among the study group. 

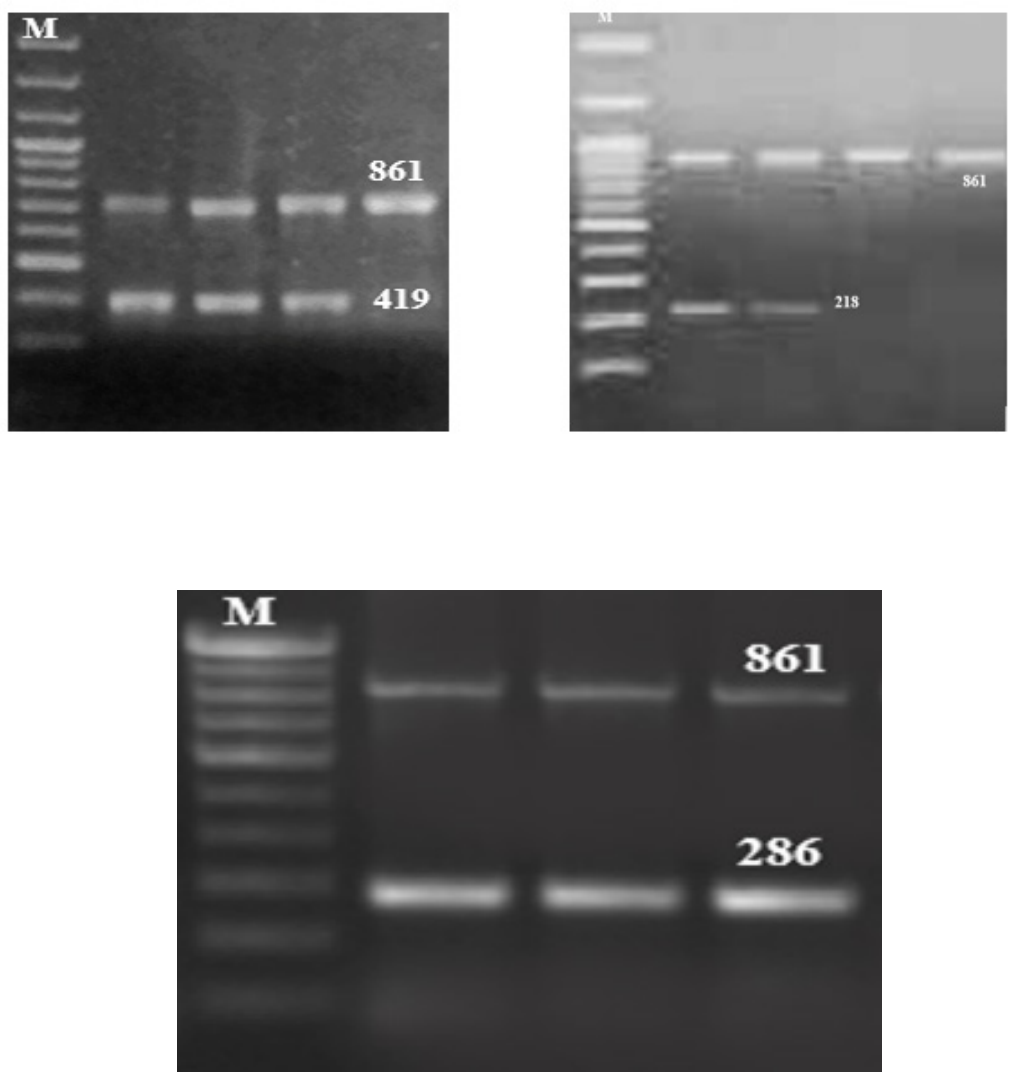

Figure 3: Gel electrophoresis picture showing IVS 1-110, IVS 1-6, IVS 1-5 mutation Lane M indicates the 100 bp ladder.

\begin{tabular}{|c|c|c|c|c|c|}
\hline \multirow{2}{*}{ Mutation type } & \multicolumn{2}{|c|}{ Adults } & \multicolumn{2}{|c|}{ Children's } & \multirow{2}{*}{ Total } \\
\hline & No & Frequency & No & Frequency & \\
\hline Mutation 1 (IVSI-110) & 9 & 20 & 5 & 31.25 & 14 \\
\hline Mutation 2 (IVSI-1) & 2 & 4.44 & 2 & 12.5 & 4 \\
\hline Mutation 3 (IVSI-6) & 2 & 4.44 & 5 & 31.25 & 7 \\
\hline Negative & 32 & 71.12 & 4 & 25 & 36 \\
\hline Total & 45 & 100 & 16 & 100 & 61 \\
\hline
\end{tabular}

IVSI-5 $(\mathrm{G} \rightarrow \mathrm{C})$ primer pair was used to amplify the $285 \mathrm{bp}$ fragment to detect the normal alleles. The IVSI-5 $(\mathrm{G} \rightarrow \mathrm{C})$ mutant primer pair was selected to amplify the 285 bp fragment for mutant allele detection. In each PCR, specific primers with the sequences were used as internal positive control that produces 861 bp fragments. Reactions were performed using PCR machine Techne (UK) under the following cycling conditions: Amplification was done with 1 cycle an initial denaturation for $5 \mathrm{~min}$ at $93^{\circ} \mathrm{C}$, followed by 25 cycles of denaturation $60 \mathrm{~s}$ and annealing at $66^{\circ} \mathrm{C}$ for 2 minutes, 1 cycle for each extension $66^{\circ} \mathrm{C}$ for 3 minutes and final extension at $72^{\circ} \mathrm{C}$ for 5 minutes and finally at $10^{\circ} \mathrm{C}$ as holding temperature [10]. $5 \mu \mathrm{l}$ of the PCR product was analyzed by gel electrophoresis.

The IVSI-1 $(\mathrm{G} \rightarrow \mathrm{A})$ primer pair was selected to amplify the 281 bp product to detect normal DNA sequence at this point, the mutant IVSI-1 $(\mathrm{G} \rightarrow \mathrm{A})$ primer pair was applied to produce the $281 \mathrm{bp}$ fragment to detect the point mutation at this position. Amplification done by 35 cycles each of; denaturation for $1 \mathrm{~min}$ at $93^{\circ} \mathrm{C}$, followed by 30 cycles, annealing at $65^{\circ} \mathrm{C}$ for $1 \mathrm{~min}$ extension at $72^{\circ} \mathrm{C}$ for 1.5 minutes and an additional $3 \mathrm{~min}$ at $72^{\circ} \mathrm{C}$ for final extension. $5 \mu \mathrm{l}$ of the PCR product was analyzed by gel electrophoresis.

$-87 \mathrm{G}$ primer pair was used to amplify the $298 \mathrm{bp}$ fragment to detect the normal alleles. The -87 mutant primer pair in the second reaction was selected to amplify the $298 \mathrm{bp}$ fragment for mutant allele detection. Amplification was done by 35 cycles each of; denaturation for $1 \mathrm{~min}$ at $94^{\circ} \mathrm{C}$, followed by 30 cycles, annealing at $64^{\circ} \mathrm{C}$ for $1 \mathrm{~min}$, extension at $72^{\circ} \mathrm{C}$ for 1 minute and an additional $3 \mathrm{~min}$ at $72^{\circ} \mathrm{C}$ for final extension.

\section{Results}

The results showed that 25 patients were positive and 36 patients were negative to 5 mutations including in the study, the frequency of IVS-I-110 positive mutations was14 (56\%) which is the most common followed by IVS-I- $6(\mathrm{~T} \rightarrow \mathrm{C})$ mutation which was 
positive in 7 patients (28\%) and IVS-I- 1 mutation which was positive in 4 (16\%) (Table 2), whereas 36 (59\%) patients showed negative for IVS-I-5 and -87 which were not detected in the present study. The gender distribution of 25 patients with positive mutations was 8 males and 17 were female (Figures 1-3). According to the age group our results were positive in 16 Children and 45 were positive in adults (Table 2), In IVSI-110 the frequency of adults were 9 while children's were 5, for IVSI-1 2 positive cases were adult while 2 were children, IVSI- 6 showed 2 positive adults and 5 in children's. Out of 61 beta-thalassemic patients the frequency of adults (15-54 years) was 45(73.8\%), and 16 (26.2\%) was children's (2year -15 years) as shown in Table 2.

\section{Discussion}

In the current study, frequency of positive mutations were observed in 25 patients (41\%), IVS-I-110(G $\rightarrow$ A) mutation was found in 14 patients (56\%), which was the commonest one followed by IVS-I-6 $(\mathrm{T} \rightarrow \mathrm{C})$ mutation which was seen in 7 patients (28\%) and IVS-I-1 mutation seen in 4 (16\%), whereas similar study done in Sudan by (Eltahirs,2013) revealed frequencies as IVS-I-110 (30\%), IVS-I-6 (12\%), IVS-I-1 (6\%), $\beta$-87 (10\%), codon $39(2 \%)$, codon $27(2 \%)$ and IVS-I-1 34(2\%). Nine patients showed negative results which correlates with this study. In correlation with study done by (Hanan and Nasir 2013) in Arab countries the most widespread mutation in Lebanon, Egypt, Syria, Jordan, Tunisia and Algeria is the IVS-I-110 (G>A) which is same as Sudan. Nevertheless, in the Eastern Arabian Peninsula, the Asian Indian mutations were (IVS-I-5 (G>C) and IVS-I ( $-25 \mathrm{bp}$ del)) are more common also support our study. In Brazil, the pattern of beta-globin mutations varies according to the region by [11]. In the South and Southeast, the $\beta 039(\mathrm{C} \rightarrow \mathrm{T})$ and $\beta+\mathrm{IVS}-\mathrm{I}-110(\mathrm{G} \rightarrow \mathrm{A})$ mutations are very frequent whereas in the Northeast, the most frequent mutations are $\beta+$ IVS-I- $6(\mathrm{~T} \rightarrow \mathrm{C})$ and $\beta 0$ IVS-I- $1(\mathrm{G} \rightarrow \mathrm{A})$. This result shown same mutations found in Sudan and Portugal. In correlation with study done in Portugal by [9] where was $\beta+\mathrm{IVS}-\mathrm{I}-110(\mathrm{G} \rightarrow \mathrm{A})$, $\beta 039(\mathrm{C} \rightarrow \mathrm{T}), \beta 0 I V S-\mathrm{I}-1(\mathrm{G} \rightarrow \mathrm{A})$, and $\beta+\mathrm{IVS}-\mathrm{I}-6(\mathrm{~T} \rightarrow \mathrm{C})$ mutations were the most common In Portugal, with frequency varying in accordance with the region, current study have shown the same results except for $\beta 039(\mathrm{C} \rightarrow \mathrm{T})$ was not observed. In Iran Statistical comparison showed that between 120 patients, IVS-II-I (G-A) $(25.4 \%)$ was the most common mutation. Other known mutation in order of frequency; IVS-I-110 (G-A) (15.4\%), IVS-I-5 (G-C) (13.3\%), FSC-8/9(+G) (5.8\%), FSC-36/37(-T) (4.6\%), Codon 30 (GC) $(2.5 \%)$, IVS-I-6 (T-C) $(2.1 \%)$ and IVS-I-1(G-A) $(0.8 \%)$, The first three mutations IVS-II-1(G-A), IVS-I-110 (G-A) andIVS-I-5 (G-C) accounted for about $54.2 \%$ of all of the mutations, which was same 5 of them detected in the current study [11]. In Malaysia, out of 169 carriers tested with the MARMS, Cd 41/42 (-TTCT), Cd 26 (A-G) HbE, IVS 1-1 (G-T), and IVS 1-5 (G-C) were the most common mutations. Whereas IVS 1-1 was the third common amongst patients in current study others were not observed (Hassan et al
2013). In Egypt, the frequency of the mutation was the same to mutations encountered in our study. The most frequently in 20 thalassemic patients mutated allele detected by Real Time PCR was the IVS I-110; 7 (35\%) patients, were heterozygous for IVS I-110 while only one was homozygous. Four patients (20\%) were double heterozygous for IVS I-110 and IVS I-6 while one patient was double heterozygous for IVS I-110 and IVS I-1. Two patients were heterozygous for IVS I-1 while one patient only was heterozygous for IVS I-6. The homozygous groups; IVS I-1, IVS I-6and IVS I-110 constituted of one patient in each group and IVS I-5 detected after sequencing [11]. In Malaysia, study conducted by study was done by [18] showed ( $\beta 0$ IVS-I- $1, \beta+$ IVS-I- 6 , and $\beta 039$ ) mutations detected by PCR/RFLP and $\beta+$ IVS-I-110, $\beta$ IVS-I- 5 mutations were detected by genes sequencing. In Lebanese $[12,13]$ study showed, IVSI-110 (29.87\%), IVSI-6 (20.74\%), IVSI-1 (14.07\%), IVSII-1 (9.13\%), Cd29 (9.13\%), and Cd30 (3.95\%) mutations are the most frequent among Lebanese thalassemic patients. These mutations are also present at high frequencies in Sudan; this study is the same as East Mediterranean region. Finally, all mutations detected in this study, IVSI-110, IVSI-6 and IVSI-1, were the commonest reported in Arab countries specially Egypt which were Mediterranean and eastern Mediterranean origin mutations. Other two mutations not detected in this study, IVSI-5 which is a mutation of Asian Indian origin, and $\beta \_87$ which is a Mediterranean origin [14-18].

\section{Conclusion}

This study detected that the most common mutations in Sudan, Khartoum state were IVSI-110 followed by IVSI-6 and IVSI-1. The results obtained shows the mutation encountered in our study were same as mutations founded in Arab countries (Lebanon, Egypt, Syria, Jordan, Tunisia and Algeria specially Egypt) countries bordering the Mediterranean and eastern Mediterranean origin. and, our mutations founded in Iran, Brazil, Portugal and only one of mutations was Asian Indian origin. We expect more mutations in Sudan if we can carry the study with large sample size and using different types of mutations.

\section{Acknowledgements}

The authors are grateful to Staffs of pediatric teaching hospital for helping in sample collection. Thanks, expressed to my sister Dr. Hanan for her help and advice. Special thanks to my husband for his support. My sincere Thanks to my family for their support, encouragement and patient.

\section{Conflict of Interest}

Authors declare that no conflict of interest exist in this paper.

\section{References}

1. Thomas B Cooley (1945) Disorders of the blood Brennemann J Practice of pediatrics, Hagerstown Md, WF Prior Company, Inc 3.

2. Hoffbrand AV, Catovsky D, Edward GD (2005) Postgraduate haematology ( $5^{\text {th }}$ edn), UK 1: 85-103. 
3. Paul Foster MD (1940) Cooley's Syndrome (Erythroblastic anemia) In A Chinese Child 59(4): 828-834.

4. Thein SL (2005) Pathophysiology of $\beta$ thalassemia-A guide to molecular therapies. Hematology Am Soc Hematol Educ Program pp. 31-37.

5. Khan, Sufyan Sohail (2018) Clinical and Demographic Variable of Beta Thalassemia Patients from Islambad and Rawalpindi. Diss. Capital University, Pakistan.

6. Thalassemia International Federation (2000) Guidelines to the Clinical Management of Thalassemia. (World Bank 2006, report of a joint WHOMarch of Dime meeting 2006).

7. Lamia'a S Saqer, Mona Z Almasri, Shahed A Almasri, Zahraa A Almasri (2016) Prevalence of Beta-thalassemia trait among students of the University College of science and technology- Palestine. IAmerican Journal of science and research 4(2): 40-46.

8. Xiong, Fu (2011) A melting curve analysis - based PCR assay for Bthalassemia mutation: a multicenter validation. The Journal of Molecular Diagnostics 13(4): 427-435.

9. Nishiguchi MK, DeSalle R Giribet G, Wheeler WC (2000) DNA isolation procedures techniques in molecular systematics and evolution pp. 247287.

10. Monalisha S Borah, Prasanta K Bhattacharya, Mauchumi S Pathak (2015) Study of IVS1-5 (C-G) Mutation in beta-thalassemia patients of tertiary care hospital of North East India. International Journal of Science and Research 6(6): 246-249.
11. Taghrid M Gaafar, Amal M EL Beshlawy, Mona I Aziz, Heba N Abdelrazik (2011) Rapid screening of $\beta$-Globin gene mutations by Real-Time PCR in Egyptian thalassemic children. Cairo, Egypt.

12. Zahed L, Talhouk R, Saleh M, Abou-Jaoudeh R, Fisher C, et al. (1997) The spectrum of b-thalassaemia mutations in the Lebanon. Hum Hered 47: 241-249.

13. Zama M Luna, Silveira (2011) Characterization of beta- thalassemia mutations in patients from the state of Rio Grande do Norte, Brazil. Genetics and Molecular biology 34(3): 425-428.

14. Hamamy HA, Al-Allawi NA (2013) Epidemiological profile of common haemoglobinopathies in Arab countries. J Community Genet 4(2): 147 167.

15. Hassan S, Ahmad R, Zakaria Z, Zulkafli Z, Abdullah WZ (2013) Detection of $\beta$-globin gene mutations among $\beta$-thalassaemia carriers and patients in Malaysia: application of multiplex amplification refractory mutation system-polymerase chain reaction. The Malaysian journal of medical sciences: MJMS 20(1): 13-20

16. (2016) National library of medicine. Beta thalassemia Genetics Home.

17. Orkin SH, Kazazian HH Jr, Antonarakis SE, Goff SC, Boehm CD, et al. (1982) Linkage of beta-thalassaemia mutations and beta-globin gene polymorphisms with DNA polymorphisms in human beta-globin gene cluster.15: 296(5858): 627-631.

18. Sana E (2013) Molecular Genetics of Beta Thalassaemia in Sudan Paperback 2013978-3659-41302-5. 